\title{
Zinner's Syndrome: A Confusing Diagnosis in the Face of Chronic Disabling Perineoscrotal Pain in the Young Subject, about a Case
}

\author{
Ntambwe Nkashama Jean-Louis*, Mouhssine Errehan, Kwizera Juvenal, \\ Mamoutou Mody Keita, Lakmichi Mohamed Amine, Dahami Zakaria, Moudouni Mohamed, \\ Sarf Ismail
}

Service d'Urologie, Chu Mohamed Vi De Marrakech, Marrakech, Maroc

Email: *ntambwejeanlouis@gmail.com

How to cite this paper: Jean-Louis, N.N., Errehan, M., Juvenal, K., Keita, M.M., Amine, L.M., Zakaria, D., Mohamed, M. and Ismail, S. (2021) Zinner's Syndrome: A Confusing Diagnosis in the Face of Chronic Disabling Perineoscrotal Pain in the Young Subject, about a Case. Case Reports in Clinical Medicine, 10, 141-145.

https://doi.org/10.4236/crcm.2021.105017

Received: March 21, 2021

Accepted: May 15, 2021

Published: May 18, 2021

Copyright $\odot 2021$ by author(s) and Scientific Research Publishing Inc. This work is licensed under the Creative Commons Attribution International License (CC BY 4.0).

http://creativecommons.org/licenses/by/4.0/

\begin{abstract}
Zinner syndrome is a rare congenital malformation related to an abnormality in the development of the Wolffian duct, the clinical picture of which consists of a triad of unilateral renal agenesis, ipsilateral seminal vesicle cyst, and obstruction of the ejaculatory duct. Chronic perineoscrotal pain may be an indication of the diagnosis of Zïnner syndrome to some extent. We report the observation of a 23-year-old patient, married and father of one child, who presented with chronic perineo-scrotal pain revealing on morphological assessment (ultrasound, uroscanner, prostatic MRI) a cystic formation of the seminal vesicle, left renal agenesis with an empty left renal compartment. Given the patient's refusal of any surgical procedure, treatment consisted of echo-guided puncture of the seminal vesicle cyst bringing back $30 \mathrm{cc}$ of a seroviscous liquid whose analysis revealed spermatozoa, without atypical cells, compatible with a cyst. The clinical evolution was marked by a progressive remission of the scrotal pain with a delay of several months.
\end{abstract}

\section{Keywords}

Agenesis, Congenital Malformation, Kidney, Perineoscrotal Pain, Seminal Vesicles, Zinner's Syndrome

\section{Introduction}

Zinner's syndrome is a rare congenital disorder related to an abnormality in the development of the Wolff duct and consists of a triad of unilateral renal agenesis, ipsilateral seminal vesicles, cyst, and obstruction of the ejaculatory duct. 
After its first description by Dr. Zinner slightly more than one hundred years ago (in 1914), about 150 to 200 cases have been published in the literature. Zinner's syndrome is usually detected in the third to fourth decade of life but can be detected earlier with the increasing use of CT and MRI scans [1].

We compiled a report based on a new case of chronic disabling perineoscrotal pain in a 23-year-old man.

\section{Patient and Observation}

This is a 23-year-old patient, married and father of one child, who presents with a chronic perineo-scrotal pain evolving for 4 years, of a heavy type, disabling and preventing any prolonged standing. This pain was not accompanied by any associated urinary problems, haemospermia or pain during sexual intercourse. Initially diagnosed as a varicocele, the patient underwent surgical treatment before being referred to our department due to the persistence of the symptoms.

The clinical examination revealed a patient in good general condition, the abdomen and external genitalia were normal, with pain provoked by palpation of the left lobe of the prostate.

Abdominal and pelvic ultrasound revealed a $22 \mathrm{~mm}$ left retrovesical cystic formation with a thin wall, a prostate of normal volume and appearance, and an empty left renal space (Figure 1).

The uroscanner confirmed the cyst of the seminal vesicle measuring $25 \times 35$ $\mathrm{mm}$ lateralized to the left, associated with left renal agenesis and a compensatory right renal hypertrophy (Figure 2). The prostatic MRI supplement allowed an accurate analysis of the relationship with neighbouring structures (Figure 3 ).

After discussion with the patient and his refusal of any surgical procedure, and given the highly symptomatic nature of the cyst, the treatment consisted of an echo-guided evacuation of the cyst bringing back about $30 \mathrm{cc}$ of a sero-viscous fluid, the cytological analysis of which revealed the presence of spermatozoa, without atypical cells, compatible with a cyst of the seminal vesicle.

The evolution marked by a regression of the symptomatology with a delay of several months.

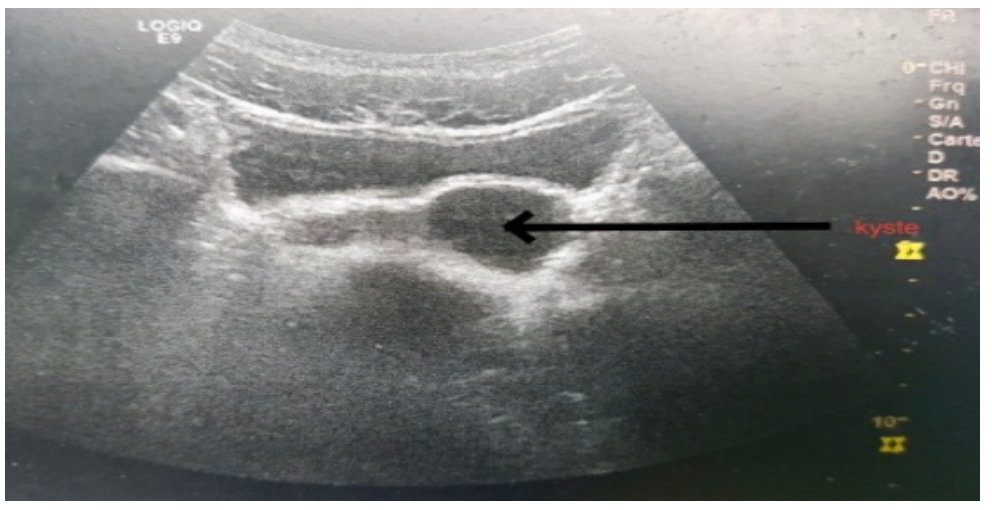

Figure 1. Abdominal-pelvic ultrasound showing a $22 \mathrm{~mm}$ left retrovesical cystic formation. 


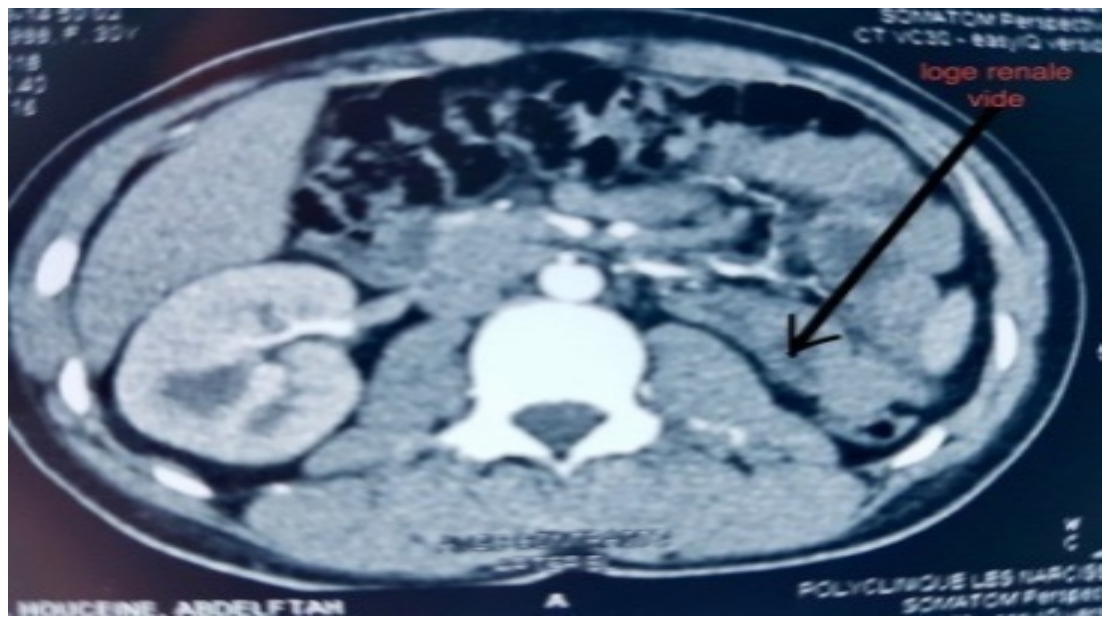

Figure 2. Uroscanner shows a hypodense retrovesical mass on the left.

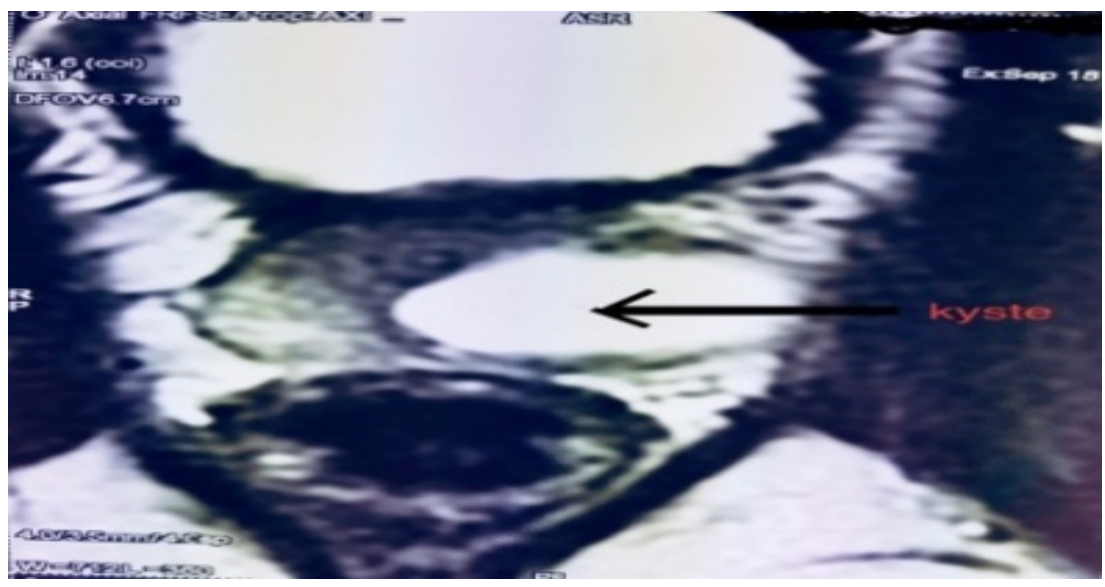

Figure 3. Prostate MRI allows a precise analysis of the relationship with neighbouring structures.

\section{Discussion}

Epidemiologically, Zinner's syndrome is a rare congenital condition that has a frequency of $0.00464 \%$ and characterized by a triad including a seminal vesicle cyst, renal agenesis and obstruction of the ipsilateral ejaculatory canal [2].

Embryologically, the mesonphric canal is responsible for the development of the upper urinary tract, epididymis, of the referential canal, seminal vesicles, ejaculating ducts, urethra, hemitrigon, and bladder neck. Aggression occurring before the 7th week of gestation of the distal part of the Wolff Canal, will cause atresia of the ejaculator canal, resulting in obstruction and dilation of the seminal vesicle, while an abnormality of the ureteral bud causes agenesis or renal dysplasia [3].

It is often during the $2 \mathrm{nd}$ and $3 \mathrm{rd}$ decade of life that the diagnosis is made because of the genital activity promoting the accumulation of seminal fluid in the vesicles.

The symptomatology is dominated by dysuria $(37 \%)$, pollakiuria $(33 \%)$, perineal pain (29\%) and epididymite (27\%) [1]. 
But in our patient there were only perineo-scrotal pains that had a particularly disabling character initially directing the etiological diagnosis towards a varicocele.

The diagnosis is essentially based on transrectal ultrasound which specifies the characteristics of the cyst of the seminal vesicle (anechogen, thin wall), and when the cyst is complicated from hemorrhage or infection, internal echoes appear. Exceptionally, the cyst may appear on ultrasound as a hypoesogenic tissue mass due to the hyperviscosity of its contents [4]. CT scans and MRI scans can be used to confirm or confirm the diagnosis in questionable cases. They also show associated anomalies [5] [6].

MRI appears to be superior to CT for the study of pelvic cystic formations [3]. MRI also allows an accurate study of cyst reports to other organs for surgical treatment and provides a differential diagnosis [5] [6] [7].

Nevertheless a cystoscopy in search of an absence of a hemi trigone is desirable.

Therapeutically, simple monitoring is recommended for non-symptomatic cysts; only symptomatic forms are indicated for essentially surgical treatment by a trans-rectal or trans-perineal guided echo aspiration of the cyst [8] [9]. In the event of recurrence after aspiration of the seminal vesicle cyst, some authors recommend a new suction and then supplement by injection of a sclerosir [9].

Another alternative is either by excision of the seminal bladder cyst by trans-vesical, extra-vesical or laparoscopic [7] [9].

Either by a transurethral detachment of the ejaculator canal and the cyst of the seminal vesicle, a complete surgical resection of the cyst by open surgery or laparoscopic, the latter pathway can even be assisted robot] [10] [11].

\section{Conclusion}

Zinner's syndrome is a rare condition that is often difficult to recognize, at first sight, our observation illustrating this by poor symptomatology made only of chronic perineo-scrotal pain. Nevertheless, the realization of a minimal workup including an adequate clinical examination and an initial radiological workup including an abdomino-pelvic ultrasound can orient the diagnosis and avoid a delay in diagnosis and management which can be deleterious on the functional level and on the patient's comfortable life.

\section{Conflicts of Interest}

The authors declare no conflicts of interest regarding the publication of this paper.

\section{References}

[1] Slaoui, A., Regragui, S., Lasri, A., et al. (2016) Zinner's Syndrome Report of Two Cases and Review of the Litterature. Basic and Clinical Andrology, 26, Article No. 10. https://doi.org/10.1186/s12610-016-0037-4

[2] Zinner, A. (1914) Einfall von Intravesikaler Samenblasenzyste. Wien Med Wochenschr, 64, 605-609. 
[3] El Mortaji, H., et al. (2018) Le syndrome de Zinner à propos d'une observation de découverte fortuite. Progrès en Urologie, 28, 464-465.

https://doi.org/10.1016/j.purol.2018.05.007

[4] Razi, A. and Imani, B. (2000) Seminal Vesicle Cyst Presenting with Lower Urinary Tract Symptoms and Huge Abdominal Mass. Journal of Urology, 164, 1309-1310. https://doi.org/10.1016/S0022-5347(05)67170-4

[5] Dahms, S.E., Hohenfellner, M., Lin, J.F., Eggersmann, C., Haupt, G. and Thuroff, J.W. (1999) Retrovesical Mass in Men: Pitfalls of Differential Diagnosis. Journal of Urology, 161, 1244-1248. https://doi.org/10.1016/S0022-5347(01)61647-1

[6] Livingston, L. and Larsen, C.R. (2000) Seminal Vesicle Cyst with Ipsilateral Renal Agenesis. American Journal of Roentgenology, 175, 177-180. https://doi.org/10.2214/ajr.175.1.1750177

[7] Ikari, O., Castilho, L.N., Lucena, R., D’Ancona, C.A. and Netto, N.R. (1999) Laparoscopic Excision of Seminal Vesicle Cysts. Journal of Urology, 162, 498-499. https://doi.org/10.1016/S0022-5347(05)68606-5

[8] Okoye, B.O., Jones, D.J., Lancashire, M.J., Brown, E.F. and Ritchie, A.W. (1995) Transvesical endoscopic drainage of a seminal vesicle cyst. British Journal of Urology, 76, 810 p. https://doi.org/10.1111/j.1464-410X.1995.tb00787.x

[9] William, R.D. and Sandlow, J.I. (1998) Surgery of Seminal Vesicles. In: Walsh, Retik, Vaughan, Wein, Eds., CampbelP s urology, Saunders, USA, 3299-3331.

[10] Mehra, S., Ranjan, R. and Garga, U.C. (2016) Zinner Syndrome-A Rare Developmental Anomaly of the Mesonephric Duct Diagnosed on Magnetic Resonance Imaging. Radiology Case Reports, 11, 313-317.

[11] Sheih, C.P., Hung, C.S., Wei, C.F. and Lin, C.Y. (1990) Cystic Dilatations within the Pelvis in Patients with Ipsilateral Renal Agenesis or Dysplasia. Journal of Urology, 144, 324-327. https://doi.org/10.1016/S0022-5347(17)39444-2 